\title{
MELHORAMENTO GENÉTICO PARA TOLERÂNCIA AO FRIO EM ARROZ IRRIGADO
}

\author{
BREEDING FOR COLD TOLERANCE IN IRRIGATED RICE
}

\section{REVISÃO BIBLIOGRÁFICA}

\author{
Renata Pereira da Cruz ${ }^{1}$ e Sandra Cristina Kothe Milach ${ }^{2}$
}

\section{RESUMO}

O melhoramento genético para tolerância ao frio é apresentado como estratégia para enfrentar o problema de temperatura baixa no Rio Grande do Sul durante o período de cultivo do arroz irrigado. A ocorrência de temperaturas baixas em outros países é comparada com a situação no sul do Brasil. Os estádios de desenvolvimento da planta mais afetados pela temperatura baixa, as estratégias de seleção disponíveis sob condiçoes controladas e os problemas encontrados para o melhoramento dessa característica são discutidos. Finalmente, estratégias de seleção promissoras baseadas em estudos de Fisiologia e Biotecnologia são apresentadas.

Palavras-chave: temperatura baixa, metodologia de seleção, estádios de desenvolvimento, Oryza sativa, fluorescência de clorofila, marcadores isoenzimáticos.

\section{SUMMARY}

Genetic breeding for cold tolerance is presented as a strategy to confront the problem of chilling temperature in Rio Grande do Sul during irrigated rice crop season. The occurence of chilling temperatures in other countries is compared to the situation in Southern Brazil. Plant developmental stages most affected by low temperatures, selection strategies available in controlled conditions and difficulties found for breeding this trait are discussed. Finally, promising selection strategies based on Physiology and Biotechnology studies are presented.

Key words: Chilling temperature, selection methodology, developmental stages, Oryza sativa, chlorophyll fluorescence, isozyme markers.

\section{INTRODUÇÃO}

O arroz é uma planta de origem tropical amplamente cultivada no mundo em uma diversidade de áreas. Essas se estendem desde a latitude $50^{\circ} \mathrm{N}$ até $40^{\circ} \mathrm{S}$, sendo cultivado desde o nível do mar até uma altitude de 3000m (JULIANO, 1993). Essa ampla faixa de cultivo abrange áreas predominantemente tropicais, mas áreas temperadas e subtropicais também são cultivadas, como é o caso do Estado do Rio Grande do Sul (RS).

Nesta extensa área geográfica utilizada para o cultivo do arroz, temperaturas não favoráveis ao desenvolvimento das plantas podem ocorrer em um ou mais estádios. A faixa de temperatura ótima para a cultura se encontra entre $25^{\circ} \mathrm{C}$ e $30^{\circ} \mathrm{C}$, e temperaturas inferiores a $20^{\circ} \mathrm{C}$, dependendo do estádio de desenvolvimento, são prejudiciais (YOSHIDA, 1981), sendo comuns em áreas temperadas e subtropicais ou nas regiões de altitude elevada nos trópicos (NANDA \& SESHU, 1979), limitando as áreas de produção e o período de cultivo.

No RS, o arroz é cultivado, de forma geral, nos meses de outubro a abril e, em algumas regiões produtoras do Estado, como Pelotas e Santa Vitória do Palmar, a temperatura mínima média

\footnotetext{
${ }^{1}$ Engenheiro Agrônomo, Mestre, aluno de Doutorado, Curso de Pós-graduação em Fitotecnia, Universidade Federal do Rio Grande do Sul (UFRGS). Bolsista CNPq. Departamento de Plantas de Lavoura, Faculdade de Agronomia, UFRGS. Av. Bento Gonçalves, 7712, C P 776, 91501-970, Porto Alegre, RS. e-mail:rfcruz@cpovo.net. Autor para correspondência.

${ }^{2}$ Engenheiro Agrônomo, Professor Adjunto, PhD., Departamento de Plantas de Lavoura, Faculdade de Agronomia, UFRGS. 
mensal no mês de outubro, quando a cultura está sendo implantada, é de $12^{\circ} \mathrm{C}$ e nos meses de janeiro e fevereiro atinge $18^{\circ} \mathrm{C}$, sendo que a mínima absoluta registrada nesta região chega a $7,4^{\circ} \mathrm{C}$ em janeiro (OLIVEIRA, 1997). A ocorrência dessas temperaturas nas fases iniciais pode causar danos no estabelecimento e estande inicial da lavoura e, mais tardiamente, pode provocar perdas no rendimento de grãos devido à esterilidade de espiguetas.

A temperatura é um fator de natureza abiótica e imprevisível e, por isso, os efeitos negativos de sua ocorrência sobre o arroz são de difícil controle em nível de manejo, o que torna a tolerância genética das cultivares extremamente importante para estabilizar o rendimento de grãos nas áreas sujeitas à ocorrência de frio.

Até o presente momento, muitos trabalhos foram publicados no mundo sobre os danos das temperaturas baixas sobre a cultura do arroz, as formas de avaliar a tolerância genética dos genótipos, a herança da tolerância ao frio e as bases fisiológicas da mesma. Faz-se necessário, assim, uma revisão que sumarize o conhecimento disponível que existe com respeito a esse assunto. Nesse sentido, esta revisão tem por objetivos abordar o melhoramento genético para tolerância ao frio como estratégia de controle para o problema, apresentando o que vem sendo feito em nível mundial, as dificuldades existentes nesse processo e algumas perspectivas futuras que se apresentam com base em estudos de Fisiologia e Biotecnologia.

\section{PANORAMA MUNDIAL}

A ocorrência de temperaturas baixas para a cultura do arroz é um problema em inúmeros países, dentre os quais citam-se Austrália, China, Colômbia, Indonésia, Japão, Coréia, Nepal e Estados Unidos (YOSHIDA, 1981). Em muitos desses países, o frio é um fator mais limitante do que é nas condições do RS e isso se deve à extensão de área atingida e à intensidade da temperatura que ocorre. No sul e sudeste da Ásia é estimado que, aproximadamente, 7 milhões de hectares são afetados pela ocorrência de temperaturas baixas, impedindo a utilização de cultivares modernas de arroz sensíveis ao frio (DEY \& UPADHYAYA, 1996). Essa área é equivalente à plantada com arroz na América Latina e Caribe juntos (PINHEIRO \& GUIMARÃES, 1994).

No Japão, a temperatura do ar pode chegar a $1^{\circ} \mathrm{C}$ na época de semeadura e até $-2^{\circ} \mathrm{C}$ na colheita, causando sérios danos ao rendimento de grãos (SHIBATA, 1979). Nas Filipinas, onde o arroz é cultivado em terraços ao longo das montanhas, a ocorrência de temperaturas baixas impede a prática de duas colheitas por ano, pois a produção é limitada às cultivares de ciclo longo adaptadas ao frio e de baixo rendimento (RONDUEN \& DUMLAN, 1979). Na Califórnia, a água de irrigação utilizada é proveniente do degelo do inverno e causa danos no estabelecimento e desenvolvimento inicial das plântulas e a baixa temperatura do ar causa retardamento do florescimento e aumento na esterilidade de espiguetas. O primeiro sintoma é visualizado claramente através do número de dias para o florescimento da cultivar IR 8, insensível ao fotoperíodo, o qual é de 90 dias nas Filipinas e de 140 dias na Califórnia (CARNAHAN et al., 1972).

Nesses países, o problema da incidência de frio sobre as plantas de arroz já vem sendo estudado há muito tempo e, por isso, estratégias próprias de seleção foram desenvolvidas por cada programa de melhoramento lá existente. Além disso, o International Rice Research Institute (IRRI) vem conduzindo experimentos cooperativos com melhoristas do mundo inteiro com os objetivos de encontrar fontes de tolerância, transferir a tolerância ao frio para cultivares semi-anãs de alto rendimento e desenvolver técnicas de teste para avaliar a tolerância ao frio do germoplasma (KANEDA \& BEACHELL, 1972). No entanto, o estádio de desenvolvimento da planta afetado pelo frio, bem como o grau de estresse (intensidade e duração do frio) variam de país para país e de região para região, assim como o conseqüente dano observado, tornando o melhoramento para tolerância ao frio em arroz extremamente dependente das condições locais. Dessa forma, a escolha do grau de tolerância ao frio que é necessário numa cultivar, e o caráter a ser selecionado (tolerância à descoloração foliar, habilidade de germinação ou fertilidade de espiguetas) vão depender de cada situação específica.

No RS, o estresse causado pelo frio é tido como a ocorrência de temperaturas entre 10 e $18^{\circ} \mathrm{C}$, as quais chegam a causar prejuízos superiores a $25 \%$ no rendimento de grãos (TERRES \& GALLI, 1985 apud TERRES, 1991). No entanto, essa situação climática ocorre, segundo TERRES (1987) apud TERRES (1991), uma vez a cada três anos e ainda assim a intensidade do frio é inferior à observada em outros locais do mundo. Assim, é provável que um nível de tolerância insuficiente para certos locais seja suficiente para as nossas condições. Baseado nisso, é fundamental que se desenvolvam estratégias próprias de seleção para as condições existentes no RS. 


\section{ESTÁDIOS DE DESENVOLVIMENTO}

Devido à origem tropical do arroz, a princípio todo e qualquer estádio de desenvolvimento da planta é sensível à temperatura baixa, porém, alguns deles têm sido constatados como mais sensíveis e têm, por isso, sido mais estudados em nível de melhoramento. Estes estádios são a germinação, o desenvolvimento inicial das plântulas e o reprodutivo. No estádio de germinação, os sintomas de dano pelo frio mais comumente observados são o atraso e a diminuição na porcentagem de germinação. Durante o estádio de plântula, o frio pode provocar atraso no desenvolvimento, redução na estatura e amarelecimento das folhas. No período reprodutivo, os sintomas de dano pelo frio são má exerção da panícula, esterilidade e manchas nas espiguetas (SOUZA, 1990). A esterilidade de espiguetas pode ser devida à inviabilidade de pólen causada pela ocorrência de frio no período de microsporogênese, quando o grão de pólen está sendo formado, e que corresponde ao período de 7 a 14 dias antes da antese (YOSHIDA, 1981; MACKILL et al., 1996); ou pode ser devido à ocorrência de frio no período do florescimento (antese) em que este prejudica a deiscência das anteras e o crescimento do tubo polínico, resultando numa baixa fecundação de espiguetas (SOUZA, 1990).

Além do estádio de desenvolvimento em que a lavoura se encontra no momento da ocorrência da temperatura baixa, o maior ou menor dano à cultura depende da intensidade e duração do frio, do manejo da cultura e da cultivar utilizada (SOUZA, 1990). Além disso, a condição nutricional das plantas em cada estádio afeta sua tolerância à temperatura baixa, tornando o problema ainda mais complicado (OKABE \& TORIYAMA, 1972).

De todos os estádios apontados acima, a microsporogênese e o florescimento são os mais sensíveis à ocorrência de frio, porém é no primeiro que ocorre a maior porcentagem de esterilidade de espiguetas (LIN \& PETERSON, 1975; YOSHIDA, 1981).

\section{ESTRATÉGIAS DE SELEÇÃO}

A seleção para uma característica determinada requer a presença do agente seletivo, neste caso a temperatura baixa. Porém, o fato desta ser de natureza abiótica a torna incontrolável em nível de campo, sendo difícil prever quando vai ocorrer, em que intensidade e qual a sua duração. Nesse sentido, pode-se observar que a seleção para tolerância ao frio a campo é uma tarefa difícil. Primeiro, não se tem como isolar o efeito da temperatura dos demais efeitos abióticos e bióticos; e segundo, quando o frio ocorre, o grau de dano observado em um genótipo depende do estádio de desenvolvimento em que ele se encontra no momento da ocorrência do estresse, tornando imprecisa a seleção de vários genótipos simultaneamente. A semeadura tardia dos genótipos, por exemplo, tentando coincidir o estádio de microsporogênese com a época mais provável de ocorrência de frio, é praticamente inviável devido a diferenças de ciclo que existem entre diferentes genótipos (BLUM, 1988). Além disso, não há garantias de que a temperatura ocorrerá na intensidade e duração suficientes para se fazer uma seleção precisa dos genótipos.

A dificuldade de se selecionar para tolerância ao frio a campo levou à necessidade de se utilizar condições controladas para que, dessa forma, possa exercer-se controle sobre a intensidade e duração da temperatura baixa. Além disso, a seleção para tolerância ao frio só será efetiva se a pressão de seleção apropriada for usada, o que torna o controle do ambiente de estresse crítico (BLUM, 1988). Num mesmo estádio de desenvolvimento, mais de uma característica pode ser avaliada e, por isso, mesmo nessas condições, a escolha da característica a ser selecionada é importante para que a avaliação da tolerância ao frio seja feita da melhor forma possível, e de forma rápida para permitir a avaliação de um grande número de genótipos ou gerações segregantes. Inúmeras metodologias foram desenvolvidas para avaliar a tolerância ao frio em diferentes estádios de desenvolvimento através da medição de diferentes características.

Na germinação, a avaliação da tolerância ao frio tem sido feita submetendo-se as sementes a temperaturas que variam desde 10 até $25^{\circ} \mathrm{C}$ por períodos de três até trinta e cinco dias. As características mais comumente medidas são a porcentagem e velocidade de germinação e o comprimento do coleóptilo e radícula (MAYA, 1988; SRINIVASULU \& VERGARA, 1988; BERTIN $\boldsymbol{e}$ al., 1996; STHAPIT \& WITCOMBE, 1998).

No estádio de plântula, o grau de estresse utilizado envolve a combinação de temperaturas que variam de 10 a $20^{\circ} \mathrm{C}$ por períodos de três até vinte e dois dias. A tolerância é avaliada através da estatura e índice de emergência, porcentagem de sobrevivência das plântulas (após um período a temperatura normal) e grau de descoloração foliar, o qual é medido numa escala visual de notas de 1 a 9 (JONES \& PETERSON, 1976; SRINIVASULU \& VERGARA, 1988; KAW, 1991; BERTIN et al., 1996).

A tolerância ao frio no estádio reprodutivo, quer seja durante a microsporogênese ou florescimento, é medida através da porcentagem de fertilidade ou esterilidade de espiguetas. As temperaturas utilizadas nos testes variam de 15 a $20^{\circ} \mathrm{C}$ por três a cinco dias (KHAN et al., 1986; KAW, 1991). 
Como se pode observar em cada estádio de desenvolvimento, diferentes níveis de estresse e caracteres são utilizados para avaliar a tolerância ao frio. A escolha do grau de estresse e do caráter a medir é uma decisão extremamente complexa, pois ao utilizar qualquer das metodologias existentes se está, na verdade, realizando uma seleção indireta sob condições controladas e que, em última instância, deverão permitir a seleção de genótipos que também expressem a tolerância ao frio em condições de campo.

A escolha do estádio de desenvolvimento no qual testar a tolerância depende de quando ocorre o problema do frio na região de cultivo para a qual o programa de melhoramento está voltado, com a praticidade de sua determinação também sendo levada em conta. $O$ estádio de microsporogênese, por exemplo, é o mais sensível à esterilidade de espiguetas, mas é de difícil determinação visual. A constatação de que há uma correlação positiva entre a esterilidade que ocorre na microsporogênese e a que ocorre no florescimento permite que se teste, neste último estádio, o qual é de mais fácil determinação (LEE, 1979). O nível de estresse a ser utilizado deve ser aquele semelhante ao que ocorre a campo ou aquele que melhor separe os genótipos tolerantes dos sensíveis.

Conhecendo-se, então, as estratégias de seleção sob condições controladas, hoje disponíveis, cabe agora a pergunta: há variabilidade genética para tolerância ao frio na espécie Oryza sativa a partir da qual se possa selecionar fontes de tolerância ao frio?

\section{FONTES DE VARIABILIDADE}

A espécie Oryza sativa possui duas variedades botânicas ou subespécies denominadas Indica e Japônica. O grupo Indica abrange as cultivares provenientes da India, China e Indonésia e o Japônica as provenientes do Japão, Coréia e Java (TAKAHASHI, 1984). Essa classificação foi feita inicialmente com base em características morfológicas que distinguem as duas subespécies, porém com o passar do tempo, características fisiológicas que mostravam variação descontínua entre os grupos passaram a ser incluídas (OKA, 1958 apud TAKAHASHI, 1984). Entre elas, tem-se a tolerância ao frio, que diferencia os dois grupos pela tolerância das cultivares do tipo Japônica e sensibilidade das cultivares Indica (TAKAHASHI, 1984). A maioria das cultivares plantadas no RS pertence a esse último grupo.

A comparação de várias cultivares de arroz pertencentes a essas duas subespécies, quanto à tolerância ao frio, foi feita em dois estádios de desenvolvimento (plântula e florescimento), com base na avaliação visual e porcentagem de fertilidade. Os resultados demonstraram que a tolerância ao frio foi maior no grupo Japônica que no grupo Indica (LI et al., 1981; SHAHI \& KHUSH, 1986).

A tolerância ao frio na germinação foi avaliada através da medição do recrescimento do coleóptilo de 24 genótipos de arroz dos grupos Indica e Japônica após serem submetidos a quatro dias a $13^{\circ} \mathrm{C}$. Os resultados demonstraram a existência de variabilidade entre os genótipos estudados, no entanto, os maiores valores de recrescimento de coleótilo foram observados em alguns genótipos do grupo Japônica. Alguns genótipos pertencentes à subespécie Indica, porém, mostraram-se similares aos do grupo Japônica de tolerância intermediária (CRUZ \& MILACH, 1999).

Na Califórnia, MACKILL \& LEI (1997) estudaram 137 cultivares de arroz classificadas nos grupos Indica e Japônica através de marcadores moleculares RAPD com relação à tolerância ao frio no estádio de plântula. Os resultados obtidos comprovam o maior grau de tolerância dos genótipos Japônica sobre os do grupo Indica. Apesar disso, segundo JENNINGS et al. (1979), há algumas cultivares do grupo Indica provenientes de regiões de latitude elevada, como Nepal, que apresentam tolerância moderada ao frio, sendo uma boa alternativa ao uso de cultivares Japônica.

A partir dos resultados acima, observa-se que há fontes de variabilidade para tolerância ao frio em vários estádios de desenvolvimento do arroz. Essas podem ser utilizadas para introdução direta como novas cultivares ou como doadoras para transferir a característica para cultivares sensíveis (SRINIVASULU \& VERGARA, 1988). A primeira alternativa depende da adaptação do genótipo ao ambiente do sul do Brasil e também da aceitabilidade fenotípica de características como tipo e qualidade de grão do genótipo. Já a segunda parece ser a de utilização mais provável, pois, como foi visto, a maioria das fontes de tolerância é do tipo Japônica, as quais não são adaptadas às condições tropicais e servem apenas como fontes de genes de tolerância. A transferência do caráter de tolerância para o material adaptado requer, no entanto, um bom conhecimento da base genética da tolerância para que se determine a melhor estratégia de melhoramento a ser adotada, ou seja, quando selecionar para o caráter, se em gerações iniciais ou avançadas.

\section{BASES GENÉTICAS DA TOLERÂNCIA AO FRIO EM ARROZ}

A variação quanto à tolerância ao frio observada entre diferentes estádios de desenvolvimento do arroz implica diferentes genes envolvidos na 
tolerância em cada estádio. Assim, a genética da tolerância ao frio em arroz tem sido estudada em cada estádio de desenvolvimento da planta separadamente. Os principais resultados obtidos são provenientes de estudos conduzidos sob condições controladas para que não haja interferência de nenhum outro fator nos resultados. Nesses estudos, a tolerância ao frio é medida de várias formas e é fundamental que se saliente que o tipo de herança encontrado é válido somente para o caráter avaliado, o material genético utilizado e o grau de estresse empregado (intensidade e período de frio).

A habilidade de germinação do arroz, medida através da porcentagem e taxa de germinação em um período de estresse de sete dias a $17^{\circ} \mathrm{C}$, mostrou uma herdabilidade que variou de 0,74 a 0,87 (STHAPIT \& WITCOMBE, 1998). Neste mesmo estudo, a tolerância ao frio no estádio de plântula, medida através do amarelecimento de folhas, apresentou uma herdabilidade variando de 0,69 a 0,73. Já KAW (1991) observou uma herdabilidade de 0,99 para esta característica, quando utilizou um estresse de $12^{\circ} \mathrm{C}$ por dez dias, o que concorda com os resultados obtidos por SHAHI \& KHUSH (1986) que encontraram um gene dominante determinando o não amarelecimento de folhas de arroz submetidas a $10^{\circ} \mathrm{C}$ por trinta dias. A herança da tolerância ao frio no estádio de plântula, avaliada através da medição da estatura em plântulas submetidas a $18^{\circ} \mathrm{C}$ por quatorze dias, evidenciou 4 a 5 genes responsáveis, com efeitos aditivos e de dominância envolvidos na expressão do caráter (LI \& RUTGER, 1980).

No estádio reprodutivo, a tolerância ao frio, medida pela exerção da panícula a campo, mostrou ser de herança monogênica, condicionada por apenas um gene dominante (MAHISHI et al., 1991; PANDEY \& GUPTA, 1993). Já a porcentagem de fertilidade de espiguetas, medida a campo, envolveu um sistema poligênico com mais de sete fatores efetivos, com efeitos de dominância e aditividade (FUTSUHARA \& TORIYAMA, 1969 apud KHAN et al., 1986). Essa mesma característica, medida sob condições controladas, em plantas submetidas a $20^{\circ} \mathrm{C}$ por cinco dias no período de antese, sugeriu uma herança poligênica, com valores de herdabilidade realizada entre 0,35 e 0,45 (KHAN $\boldsymbol{e t}$ al., 1986).

Os dados acima demonstram que, mesmo para uma mesma característica de tolerância avaliada, dependendo do grau de estresse utilizado, os resultados de herança ou herdabilidade variam. Portanto, para que estudos desse tipo tenham aplicabilidade é importante que o nível de estresse utilizado seja definido (DATTA \& SIDDIQ, 1983).
De forma geral, a herança da tolerância ao frio em arroz parece ser oligogênica e, em muitos dos estudos, a herdabilidade parece ser moderada à alta. Apesar desses resultados indicarem que os caracteres de tolerância avaliados são de fácil seleção e incorporação nos genótipos adaptados, muitas dificuldades ainda existem no melhoramento para tolerância ao frio em arroz.

\section{DIFICULDADES DO MELHORAMENTO PARA TOLERÂNCIA AO FRIO EM ARROZ}

O melhoramento para tolerância ao frio em arroz apresenta vários problemas e alguns dos principais fatores responsáveis são enumerados abaixo:

\section{1) Cruzamentos Indica $x$ Japônica}

Tem sido relatado um alto grau de esterilidade na geração $F_{1}$ de cruzamentos entre cultivares do tipo Indica com as do tipo Japônica, o que diminui o número de recombinantes obtidos e dificulta a transferência gênica entre essas duas subespécies. Segundo FORNASIERI FILHO \& FORNASIERI (1993), a fertilidade de híbridos $\mathrm{F}_{1}$ varia de 0 a $33 \%$. Além disso, algumas características indesejáveis existentes nas cultivares do tipo Japônica também tornam a introgressão de genes entre essas subespécies problemática, uma vez que, juntamente com a tolerância ao frio, serão introduzidos caracteres indesejáveis, como tipo de grão e de planta.

\section{2) Base genética}

Muitos estudos têm apontado que a tolerância ao frio no estádio reprodutivo é de herança quantitativa (ACHARYA \& SHARMA, 1983; KHAN et al., 1986), o que dificulta a seleção para tolerância nesse estádio, que é o mais sensível e onde se observam maiores perdas no rendimento de grãos.

\section{3) Metodologia de seleção}

Alguns equipamentos, tais como câmaras de incubação e fitotrons, apesar de permitir o controle da temperatura, são impraticáveis de utilização para seleção nas gerações segregantes dos programas de melhoramento, em que muitas plantas devem ser avaliadas simultaneamente.

Em alguns dos métodos já mencionados, a avaliação do caráter é trabalhosa e demorada, como a medição do comprimento do coleóptilo ou a porcentagem de esterilidade de espiguetas. Assim, não são adequados em programas de melhoramento onde 
um grande número de linhagens devem ser avaliadas. Além disso, muitas características são estimativas visuais de dano que fazem uso de escalas arbitrárias baseadas na severidade dos sintomas, como é o caso do grau de amarelecimento das folhas. Essas escalas são subjetivas e medem efeitos indiretos do dano pelo frio; sua avaliação é demorada e requer um período de temperatura normal para o aparecimento dos sintomas de dano (STHAPIT et al.,1995). Alguns métodos têm a desvantagem de ser destrutivos, como é o caso da avaliação da porcentagem de sobrevivência de plântulas.

Por fim, a variação da temperatura a campo, a presença de fatores bióticos e a interação com outros elementos climáticos têm dificultado a correlação entre os resultados obtidos no ambiente controlado e no campo, limitando a aplicabilidade da seleção sob condições controladas (BLUM, 1988). Não obstante, JONES \& PETERSON (1976) obtiveram correlações significativas entre a estatura de plântulas medida sob condições de laboratório e a velocidade e índice de emergência a campo.

\section{4) Correlação entre a tolerância ao frio nos dife- rentes estádios de desenvolvimento}

Uma cultivar de arroz pode ser tolerante ao frio no estádio vegetativo e sensível no reprodutivo, ou vice-versa. Isso provavelmente decorre de diferentes genes de tolerância e diferentes mecanismos fisiológicos envolvidos na tolerância ao frio em cada estádio. No entanto, a falta de correlação entre a tolerância ao frio num estádio e outro torna o melhoramento para essa característica bastante complicado quando o objetivo é incorporar tolerância em vários estádios (DATTA \& SIDDIQ, 1983), pois se este for o caso, será necessário realizar seleção em cada um deles separadamente. A existência de correlação entre diferentes estádios quanto à tolerância ao frio seria vantajosa por permitir, inclusive, seleção indireta para a característica, por exemplo, a seleção para tolerância ao frio no estádio reprodutivo poderia ser feita mais precocemente em plântulas, onde o espaço requerido é menor e se pode avaliar maior número de indivíduos simultaneamente.

Infelizmente, tem sido relatado que a tolerância ao frio em arroz nos estádios vegetativo e reprodutivo é governada por fatores genéticos diferentes e que atuam em direções opostas (KAW \& KHUSH, 1986; SHAHI \& KHUSH, 1986). Num estudo com 54 híbridos Japônica x Indica e 48 híbridos Indica $x$ Indica e os respectivos genitores, foi encontrado que a correlação genotípica entre a estatura de plântula e o número de espiguetas férteis foi de $-0,50$ e entre a porcentagem de sobrevivência de plântulas e o número de espiguetas férteis foi de -0,66 (KAW, 1991). No mesmo estudo, foi observada uma correlação de 0,87 entre a estatura de plântulas e a porcentagem de sobrevivência das mesmas. Assim, num mesmo estádio de desenvolvimento, a correlação entre diferentes características é geralmente positiva e alta, demonstrando que apenas a seleção de uma delas já é suficiente.

O conhecimento das correlações existentes entre diferentes características é importante pois, se duas ou mais delas forem positiva e altamente correlacionadas, a seleção de apenas uma delas já será eficiente, podendo-se selecionar pela característica mais fácil de avaliar, agilizando o processo de melhoramento.

\section{PERSPECTIVAS FUTURAS}

O melhoramento para tolerância ao frio em arroz foi abordado de forma a apresentar os principais resultados obtidos pela pesquisa e as principais dificuldades existentes. Pelo que foi discutido até aqui, nota-se que seria extremamente interessante se o melhoramento genético pudesse utilizar novas ferramentas para tornar o processo de seleção de genótipos tolerantes ao frio mais ágil e preciso.

Atualmente, muito vem sendo elucidado a respeito dos mecanismos fisiológicos da tolerância ao frio em arroz, e o conhecimento desses mecanismos será, sem dúvida, de extrema importância para que novas estratégias de seleção possam ser desenvolvidas para uso nos programas de melhoramento.

O dano em decorrência do frio que é fenotipicamente visualizado pelo melhorista é, na verdade, resultado de uma disfunção celular que ocorre em plantas de arroz quando expostas a temperaturas baixas (RAISON \& ORR, 1987). De forma geral e bastante resumidamente, pode-se dizer que o mecanismo fisiológico primário envolvido na tolerância ao frio é a conservação da atividade e funcionamento da membrana celular a baixas temperaturas. O prejuízo dessa atividade em função do frio tem uma implicação em vários processos fisiológicos vegetais, dentre eles a atividade do cloroplasto, o funcionamento celular, as relações hídricas e, por fim, o crescimento (BLUM, 1988). Com base no conhecimento de que a atividade do cloroplasto é afetada diretamente pelo frio é que a fluorescência de clorofila tem sido usada como forma de quantificar a tolerância ao frio no estádio de plântula. Essa técnica se baseia no fato de que durante o processo de fotossíntese uma pequena porção de luz é reemitida pela molécula de clorofila, a qual é denominada fluorescência de clorofila (STHAPIT $\boldsymbol{e t} \boldsymbol{a l}$., 1995). A medição da quantidade de fluorescência 
emitida permite avaliar o funcionamento do sistema fotossintético em condições de estresse por frio. Quanto maior o nível de fluorescência emitido, menor é o dano ao aparelho fotossintético e à molécula de clorofila. Esta é, então, uma forma precisa de avaliar diretamente a tolerância ao frio no estádio de plântula, pois o dano é medido diretamente e não indiretamente como feito através do grau de amarelecimento das folhas.

O método é bastante simples e consiste em submeter folhas (coletadas em plantas sob estresse de frio) a um período de aclimatação no escuro, também sob frio, e após expor as folhas à radiação medindo a fluorescência de clorofila com o auxílio de um fluorímetro. Utilizando essa técnica, RHO (1985) avaliou cultivares Japônica e Indica submetidas a $10^{\circ} \mathrm{C}$ por oito dias. As mudanças na fluorescência de clorofila foram expressas como porcentagem do controle (mantido a $27^{\circ} \mathrm{C}$ ) e comparadas com a estimativa visual do dano de frio feito na escala de 1 a 9. A fluorescência de clorofila de algumas cultivares Japônica aumentou durante o tratamento de frio, sendo 23 a $34 \%$ superior ao controle; e nas cultivares Indica ela decresceu em até $98 \%$. Esse método permite aos melhoristas fazer um "screening" rápido de grande número de plantas para tolerância ao frio, com a vantagem de ser sensível, reproduzível, não-destrutivo, econômico e permitir detectar o dano antes do aparecimento dos sintomas (WILSON \& GREAVES, 1990).

$\mathrm{Na}$ área de Biotecnologia, inúmeras possibilidades se apresentam. O cultivo de anteras tem sido utilizado para o desenvolvimento de genótipos tolerantes ao frio, com a finalidade de acelerar a avaliação e teste de progênies derivadas de cruzamentos entre genótipos tolerantes e sensíveis (GUPTA $\boldsymbol{e t} \boldsymbol{a l} ., 1996)$. A variação somaclonal e a seleção "in vitro" para o melhoramento da tolerância ao frio em arroz foram empregadas com sucesso, tendo sido regeneradas plantas mais tolerantes que as plantas controles (BERTIM \& BOUHARMONT, 1997; BERTIN et al., 1997).

A transformação genética também é sugerida como uma estratégia biotecnológica alternativa no melhoramento para tolerância ao frio em arroz. Através dela já foram obtidas plantas de tabaco com menor sensibilidade ao frio (MURATA et al., 1992 apud UCHIMIYA $\boldsymbol{e t} \boldsymbol{a l}$. , 1993), porém nenhum resultado concreto foi relatado até o momento em arroz.

O uso de marcadores moleculares também é uma possibilidade interessante para seleção indireta da tolerância ao frio. Os marcadores de DNA já vêm sendo usados em arroz para o desenvolvimento de mapas moleculares e para o mapeamento de caracteres relacionados ao rendimento $(\mathrm{McCOUCH}$ et al., 1988; LIN et al., 1996; CHEN et al., 1997), mas até hoje nenhum deles foi relacionado à tolerância ao frio. Esse não é o caso dos marcadores isoenzimáticos, mais especificamente o sistema esterase, que se apresenta como uma provável ferramenta na seleção de genótipos de arroz tolerantes ao frio. Neste sistema isoenzimático, dois locos, o Est-2 e Est-3 já foram associados à tolerância ao frio em arroz (MAJUMDER $\boldsymbol{e}$ t $\boldsymbol{a l}$., 1989; NAGAMINE \& NAKAGAHRA, 1991). No primeiro, o alelo Est-2 ${ }^{0}$ foi encontrado em genótipos tolerantes e os alelos $E s t-2^{l}$ e Est- $2^{2}$ em sensíveis, independente da subespécie a que pertenciam. Além disso, o padrão isoenzimático identificado variou conforme o estádio de desenvolvimento em que o genótipo se mostrava tolerante, sendo identificado o alelo Est-2 $2^{0}$ no estádio vegetativo onde havia tolerância ao frio e o alelo Est-2 ${ }^{2}$ no estádio reprodutivo, onde era sensível (MAJUMDER et al., 1989). Apesar do caráter tolerância ao frio ser provavelmente um caráter de herança poligênica, o grau de tolerância parece ser influenciado pelo padrão isoenzimático da esterase2. Se confirmada esta associação entre o padrão isoenzimático da esterase 2 e a tolerância ao frio, será possível utilizar essa técnica na seleção indireta do caráter em programas de melhoramento.

\section{CONSIDERAÇÕES FINAIS}

Para o melhoramento genético de um caráter, a existência de variabilidade é o ponto-chave. No caso da tolerância ao frio em arroz, esta pode, como foi visto, ser gerada através da introdução de germoplasma tolerante ao frio, provavelmente do tipo Japônica. A partir daí ela pode ser transferida para o material adaptado existente no programa através de cruzamentos do tipo Indica x Japônica, os quais se sabe têm problemas de esterilidade e, portanto, recombinação. A avaliação do germoplasma disponível no programa de melhoramento quanto à tolerância ao frio também é aconselhável para verificar possíveis fontes de tolerância, ao menos moderada. Para isso, é preferível uma avaliação cuidadosa do material sob condições controladas em um ou mais estádios para que as fontes de tolerância sejam identificadas da forma mais precisa possível.

A metodologia de seleção nas gerações segregantes dependerá do estádio de desenvolvimento para o qual se quer tolerância ao frio, do grau de tolerância necessário e da infra-estrutra disponível no programa. As metodologias de seleção sob condições controladas permitem a avaliação de um grande número de plantas, porém, dependendo do tipo de característica que está sendo medida, o método pode se tornar de avaliação demorada ou de menor precisão. 
A técnica de fluorescência de clorofila e a análise do padrão isoenzimático da esterase são boas alternativas para a seleção da tolerância em populações segregantes ou mesmo para fazer um screening do germoplasma do programa; com os testes a campo, que apesar de apresentarem uma série de limitações, sendo indicados apenas para avaliação de gerações avançadas, em que há possibilidade de repetição e, assim, minimizar os efeitos de ambiente. Nesse caso, deve-se tomar o cuidado de semear o material de forma a coincidir a época mais provável de ocorrência de frio com o estádio de desenvolvimento para o qual se quer a tolerância.

O melhoramento para tolerância ao frio em arroz não é uma tarefa fácil, no entanto, em outros locais do mundo onde o problema é mais sério, cultivares com tolerância adequada já foram obtidas. O caminho para o desenvolvimento de cultivares tolerantes nas condições do RS deve envolver, sem dúvida, a adoção das várias estratégias que foram apresentadas para tornar o processo de melhoramento desse caráter mais ágil e preciso. $\mathrm{O}$ ponto de partida está no uso das ferramentas disponíveis para o conhecimento do germoplasma existente nos nossos programas de melhoramento. Somente a partir da caracterização precisa dos genótipos será possível obter avanços no melhoramento de arroz para tolerância ao frio no sul do Brasil.

\section{REFERÊNCIAS BIBLIOGRÁFICAS:}

ACHARYA, S., SHARMA, K.D. Genetics of cold tolerance at rice reproductive stage. International Rice Research Newsletter, Los Baños, v.8, n.2, p.10-11, 1983.

BERTIN, P., KINET, J.M., BOUHARMONT, J. Evaluation of chilling sensitivity in different rice varieties. Relationship between screening procedures applied during germination and vegetative growth. Euphytica, Dordrecht, v.89, p.201-210, 1996.

BERTIN, P., BOUHARMONT, J. Use of somaclonal variation and in vitro selection for chilling tolerance improvement in rice. Euphytica, Dordrecht, v.96, p.135-142, 1997.

BERTIN, P., BUSOGORO, J.P., TILQUIN, J.P., et al. Field performance of rice somaclones at low temperature: effects of callus chilling treatment. Crop Science, Madison, v.37, p.1943-1950, 1997.

BLUM, A. Plant breeding for stress environments. Boca Raton : CRC, 1988. Cap. 5 : Cold resistance: p.99-132.

CARNAHAN, H.L., ERICKSON, J.R., MASTENBROEK, J.J. Rice breeding. Los Baños : International Rice Research Institute, 1972. Tolerance of rice to cool temperatures USA: p.535-540.

CHEN, X., TEMNYKH, S., XU, Y., et al. Development of a microsatellite framework map providing genome-wide coverage in rice (Oryza sativa $\mathbf{L}$.). Theoretical and Applied Genetics, Berlin, v.95, p.553-567, 1997.
CRUZ, R.P. da, MILACH, S.C.K. Avaliação de genótipos de arroz quanto à tolerância ao frio na germinação. In: REUNIÃO DA CULTURA DO ARROZ IRRIGADO, 23., 1999, Pelotas, RS. Resumos... Pelotas : Empresa Brasileira de Pesquisa Agropecuária, 1999. 727p. p.42-44.

DATTA, D., SIDDIQ, E.A. Genetic analysis of cold tolerance at seedling phase in rice. Indian Journal of Genetics and Plant Breeding, New Delhi, v.43, p.345-349, 1983.

DEY, M.M.; UPADHYAYA, H.K. Yield loss due to drought, cold and submergence in Asia. In: EVENSON, R.E., HERDT, R.W., HOSSAIN, M. (Eds.) Rice research in Asia. Progress and priorities. Wallingbord : Cab International, 1996. p.291-303.

FORNASIERI FILHO, D., FORNASIERI, J.L. Manual da cultura do arroz. Jaboticabal : FUNEP, 1993. 221p.

GUPTA, H.S., BHUYAN, R.N., PATTANAYAK, A. Development of cold-tolerant rice through anther culture. International Rice Research Notes, Los Baños, v.21, n.1, p.20, 1996 .

JENNINGS, P.R.; COFFMAN, W.R.; KAUFFMAN, H.E. Rice improvement. Los Baños : International Rice Research Institute, 1979. Cap. 10: Temperature tolerance: p.183-186.

JONES, D.B., PETERSON, M.L. Rice seedling vigor at suboptimal temperatures. Crop Science, Madison, v.16, p.102$105,1976$.

JULIANO, B.O. Rice in human nutrition. Los Baños: International Rice Research Institue and Food and Agriculture Organization of the United Nations, 1993. Cap.1: Introduction: p.1-15.

KANEDA, C.; BEACHELL, H.M. Rice breeding. Los Baños: International Rice Resarch Institute, 1972. Resistance of Japonica $x$ Indica breeding lines to low temperatures: p.541545.

KAW, R.N. Genetic parameters of cold tolerance in rice. Indian Journal of Genetics, New Delhi, v.51, p.59-65, 1991.

KAW, R.N., KHUSH, G.S. Combining ability for lowtemperature tolerance in rice. In: INTERNATIONAL RICE GENETICS SYMPOSIUM, 1, 1986. Los Baños. Proceedings... Los Baños : International Rice Research Institute, 1986, 931p. p. 93-612.

KHAN, D.R., MACKILL, D.J., VERGARA, B.S. Selection for tolerance to low temperature sterility at anthesis in rice. Crop Science, Madison, v.26, p.694-698, 1986.

LEE, J.H. Report of a rice cold tolerance workshop. Los Baños : International Rice Resarch Institute, 1979. Screening methods for cold tolerance at crop experiment station phytotron and at Chuncheon: p.77-90.

LI, C.C., RUTGER, J.N. Inheritance of cool-temperature seedling vigor in rice and its relationship with other agronomic characters. Crop Science, Madison, v.20, p.295298, 1980.

LI, T.G., VISPERAS, R.M., VERGARA, B.S. Correlation of cold tolerance at different growth stages in rice. Acta Botanica Sinica, Beijing, v.23, p.203-207, 1981. 
LIN, S.S., PETERSON, M.L. Low temperature-induced floret sterility in rice. Crop Science, Madison, v.15, p.657-660, 1975.

LIN, H.-X., QIAN, H.-R., ZHUANG, J.-Y., et al. RFLP mapping of QTLs for yield and related characters in rice (Oryza sativa L.) Theoretical and Applied Genetics, Berlin, v.92, p.920927, 1996.

MACKILL, D.J., COFFMAN, W.R., GARRITY, D.P. Rainfed lowland rice improvement. Manila : International Rice Research Institute, 1996. 242p.

MACKILL, D.J., LEI, X. Genetic variation for traits related to temperate adaptation of rice cultivars. Crop Science, Madison, v.37, p.1340-1346, 1997.

MAHISHI, D.M., MAHADEVAPPA, M., REDDY, P.G Inheritance of panicle exsertion in Oryza sativa under low temperature. In: INTERNATIONAL RICE GENETICS SYMPOSIUM, 2., 1991, Los Baños. Proceedings... Los Baños : International Rice Research Institute, 1991, 844p. p.175-177.

MAJUMDER, M.K., SESHU, D.V., SHENOY, V.V. Implication of fatty acids and seed dormancy in a new screening procedure for cold tolerance in rice. Crop Science, Madison, v.29, p.1298-1304, 1989

MAYA, O.I.M. Identificacion de metodologias para la evaluacion de tolerancia a temperaturas bajas en arroz (Oryza sativa L.). Palmira, 1988. 123p. Trabalho de Graduação (Graduação em Engenharia Agronômica) Facultad de Ciencias Agropecuarias, Universidad Nacional de Colombia, 1988 .

McCOUCH, S.R., KOCHERT, G., YU, Z.H., et al. Molecular mapping of rice chromosomes. Theoretical and Applied Genetics, Berlin, v.76, p.815-829, 1988.

NAGAMINE, T., NAKAGAHRA, M. Genetic control of chilling injury in rice seedlings detected by low-temperature treatment. In: INTERNATIONAL RICE GENETICS SYMPOSIUM, 2, 1991, Los Baños. Proceedings... Los Baños : International Rice Research Institute, 1991, 844p. p.737-739.

NANDA, J.S., SESHU, D.V. Report of a rice cold tolerance workshop. Los Baños : International Rice Research Institute, 1979. Breeding strategy for cold-tolerant rices: p.91-99.

OKABE, S., TORIYAMA, K. Rice breeding, Los Baños : International Rice Resarch Institute, 1972. Tolerance to cool temperatures in Japanese rice varieties: p.529-531.

OLIVEIRA, H. T. de. Climatologia das temperaturas mínimas e probabilidade de ocorrência de geada no Estado do Rio Grande do Sul. Porto Alegre - RS, 1997. 81p. Dissertação (Mestrado em Fitotecnia) - Curso de Pós-graduação em Fitotecnia, Universidade Federal do Rio Grande do Sul, 1997.

PANDEY, D.K., GUPTA, H.S. Genetics of panicle exsertion in cold-tolerant rice (Oryza sativa). Plant Breeding, Berlin, v.111, p.82-85, 1993

PINHEIRO, B. da S., GUIMARÃES, E.P. Arroz na América Latina: perspectivas para o incremento da produção e do potencial produtivo. In: CONFERÊNCIA INTERNACIONAL DE ARROZ PARA A AMÉRICA LATINA E O CARIBE, 9
1994, Goiânia, GO. Anais... Goiânia : Embrapa-CNPAFAPA, 1994. v.2. 256p. (Embrapa-CNPAF. Documentos, 62).

RAISON, J.K., ORR, G.R. Proposal for a better understanding of the molecular basis of chilling injury. In: WANG, C.Y. (Ed.) Chilling injury of horticultutral crops. London : CRC, 1987. p.145-164

RHO, Y.D. Assesment of cold tolerance of Korean rice varieties by chlorophyll fluorescence analysis. International Rice Research Notes, Los Baños, v.10, p.14-16, 1985.

RONDUEN, A., DUMLAN, R. Report of a rice cold tolerance workshop. Los Baños : International Rice Research Institute, 1979. Low-temperature problem and research activities in the Philippines: p.69-75.

SHAHI, B.B., KHUSH, G.S. Genetic analysis of cold tolerance in rice. In: INTERNATIONAL RICE GENETICS SYMPOSIUM, 1., 1986, Los Baños. Proceedings... Los Baños : International Rice Research Institute, 1986. 931p. p.429-435.

SHIBATA, M. Report of a rice cold tolerance workshop. Los Baños : International Rice Research Institute, 1979. Progress in breeding cold-tolerant rice in Japan: p.21-24.

SOUZA, P.R. Alguns aspectos da influência do clima temperado sobre a cultura do arroz irrigado, no sul do Brasil. Lavoura Arrozeira, Porto Alegre, v.43, n.389, p.9-11, 1990.

STHAPIT, B.R., WITCOMBE, J.R. Inheritance of tolerance to chilling stress in rice during germination and plumule greening. Crop Science, Madison, v.38, p.660-665, 1998

STHAPIT, B.R., WITCOMBE, J.R., WILSON, J.M. Methods of selection for chilling tolerance in Nepalese rice by chlorophyll fluorescence analysis. Crop Science, Madison, v.35, p.90-94, 1995 .

SRINIVASULU, K., VERGARA, B.S. Screening of upland and short duration rice varieties for cold tolerance at seedling emergence stage. Oryza, Cuttack, v.25, p.87-90, 1988.

TAKAHASHI, N. Differentiation of ecotypes in Oryza sativa L. In: TAKAHASHI, N., TSUNODA, S. (Eds). Biology of rice. Tokyo : Japan Sci Soc, 1984. p.31-67.

TERRES, A. L. Melhoramento de arroz irrigado para tolerância ao frio no Rio grande do Sul - Brasil. In: REUNIÓN SOBRE MEJORAMIENTO DE ARROZ EN EL CONO SUR, 1991. Goiânia. Trabajos... Montevideo : IICA - PROCISUR, 1991. 150p. p.91-103. (Diálogo / IICA -PROCISUR; n 33).

UCHIMIYA, H., PATENA, L.F., BRAR, D.S. International Crop Science I. Madison : Crop Science Society of America, 1993. Cap.83: Gene transfer technology in higher plants: p.633-640.

WILSON, J.M., GREAVES, J.A. Assessment of chilling sensitivity by chlorophyll fluorescence analysis. In: WANG, C.Y. (Ed) Chilling injury of horticultural crops. London: CRC, 1990. p.130-139.

YOSHIDA, S. Fundamentals of rice crop science. Los Baños: International Rice Research Institute, 1981. Cap.1: Growth and development of the rice plant: p.1-63. 